Irma Pérez-Silva, Carlos A. Galán-Vidal, María T. Ramírez-Silva, Giaan A. Álvarez Romero and Ma. Elena Páez-Hernández*

\title{
Evaluation of activated composite membranes for the facilitated transport of phenol
}

https://doi.org/10.1515/epoly-2018-0002

Received January 5, 2018; accepted March 14, 2018; previously published online April 27, 2018

\begin{abstract}
In this work the results on the first use of an activated composite membrane (ACM) containing Cyanex 923 for the extraction and transport of phenol are presented. A new dense layer-ACM configuration constituted by piperazine showed better stability than that prepared with 1,3-phenylenediamine. The effects of several parameters on the transport of phenol such as feed phase $\mathrm{pH}$, carrier concentration and stripping phase composition were evaluated. The performance of the membrane was also evaluated during continuous additions of phenol and for a long period of time, observing the same rate of extraction and reextraction. Moreover, phenol transport was evaluated starting from synthetic wastewater of resin production plants type. The results exhibit the potential use of ACMs in the elimination and transport of organic species, even when analyte is initially found in complex solutions.
\end{abstract}

Keywords: activated composite membrane; Cyanex 923; phenol; resin manufacturing wastewater; transport.

\section{Introduction}

Phenol is a highly toxic compound, which can be found in various concentrations in wastewater. Phenolic compounds are present in different industrial processes, such as in the production of phenolic resins, colorants

*Corresponding author: Ma. Elena Páez-Hernández, Área Académica de Química, Universidad Autónoma del Estado de Hidalgo, Carr. Pachuca-Tulancingo Km. 4.5, C.P. 42184. Mineral de la Reforma, Hidalgo, México, Tel.: +527717172000 ext. 2217, +52 7717172000 ext.6502, e-mail: paezh@uaeh.edu.mx. http://orcid.org/0000-0003-0118-6049 Irma Pérez-Silva, Carlos A. Galán-Vidal and Giaan A. Álvarez Romero: Área Académica de Química, Universidad Autónoma del Estado de Hidalgo, Carr. Pachuca-Tulancingo Km. 4.5, C.P. 42184. Mineral de la Reforma, Hidalgo, México

María T. Ramírez-Silva: Área de Química Analítica, Laboratorio R-105, Universidad Autónoma Metropolitana-Iztapalapa, San Rafael Atlixco 186, Col. Vicentina, C.P. 09340. AP 55-534, Ciudad de México, México or pesticides, etc. (1). Due to its toxicity, the EPA has set a limit of $2 \mathrm{mg} \mathrm{l}^{-1}$ phenol in water (2), while the Mexican government establishes a maximum level of $0.001 \mathrm{mg} \mathrm{l}^{-1}$ in water for human consumption (3).

Phenol removal from water comprises several strategies $(1,4)$, some of them destructive. Among these, total oxidation stands out due the great variety of modalities it covers. Thus, oxygen or air has been used for phenol oxidation in the presence or absence of catalysts as noble metals or transition metal cations, frequently supported on alumina or carbon. Additionally oxidation with ozone, hydrogen peroxide and chlorine has been reported as well the electrochemical phenol direct oxidation or indirect, including electro-Fenton (5). However, in these cases, an adequate oxidant dosage and appropriated physical and chemical conditions are necessary in order to avoid the appearance of intermediates and to assure the diminishing of phenolic compounds (6).

An example of a non-destructive phenol recovery technique is liquid-liquid extraction with various extractants such as cumene, TBP, hexane, 2-octanol or kerosene with recovery percentages from 70 to $99 \%$. Distillation, which has the advantage of recovering several compounds at a time, is a strategy designed for samples with concentrations higher than $3000 \mathrm{mg} \mathrm{l}^{-1}$ (4).

Other non-destructive methods are based on the sorption of phenol in various materials such as activated carbon or chitosan. Others are based on the use of polymeric adsorbent materials made of styrene and divinylbenzene with a hydrophobic structure, different particle size, surface area and degree of cross-linking (7). Solvent impregnated resins (SIRs) have also been used due to the interaction between the extractant agent and phenol (8-10); thus, Amberlite XAD-16 resin impregnated with Cyanex 923 was used in order to improve the extraction rate. However, in both cases it is necessary to desorb the phenol after its extraction for a later process.

Considering the above, membrane technology offers the possibility to extract and release an analyte by means of a simple and continuous procedure. A kind of membrane that gathers the selectivity of liquid membranes and stability of asymmetric membranes is the activated composite membrane (ACM) (11). The ACM consists of a 
dense layer that contains an extractant, all supported in a porous polymeric support. The ACMs have been used for the removal of metal ions with excellent results in extraction percentage $(>95 \%)$ and short removal and separation times $(<2$ h) (12-16). However, the application of this type of membrane for removal and transport of organic compounds is scarce, so the present work is an important contribution in the field of membrane separation.

\section{Experimental}

\subsection{Materials}

All commercial reagents were ACS grade and purchased from Aldrich (St. Louis, MO, USA). The Cyanex 923 extractant was kindly supplied by Cytec Industries Inc. (Hermosillo, Mexico); this compound has shown affinity for phenolics compounds in previous reports (17-20).

\subsection{Preparation of activated composite membrane}

The activated composite membrane was prepared according Benavente et al. (21). First the porous layer is prepared by dissolving polysulfone in $\mathrm{N}, \mathrm{N}^{\prime}$-dimethylformamide $(15 \% \mathrm{w} / \mathrm{v})$ and then depositing it on a nonwoven paper support (Hollytex 3329, Talas Co., NY, USA). The porous membrane is then formed by phase inversion, submerging it in a water bath. On the top of the previous porous layer, a dense layer containing the carrier agent (Cyanex 923) was formed by interfacial polymerization due to the interaction of two different phases: one of them, the diamine aqueous solution $(2 \% \mathrm{w} / \mathrm{v})$ (1,3-phenylenediamine or piperazine), and the other, a kerosene organic solution containing 1,3,5-benzenetricarbonyl chloride $(0.1 \% \mathrm{w} / \mathrm{v})$ and the organic Cyanex 923 ligand. The prepared ACM was washed with deionized water and dried in an oven for $30 \mathrm{~min}$ at $60^{\circ} \mathrm{C}$. An inactivated composite membrane (ICM) was prepared similarly to an ACM without including the Cyanex organic ligand.

\subsection{ACM characterization}

ACM was analyzed by Raman spectroscopy using a PerkinElmer Spectrum GX system (Waltham, MA, USA) in a spectral window of 400-3400 $\mathrm{cm}^{-1}$. Energy dispersive X-ray spectroscopy was done using a JEOL JSM-6300 (Peabody, MA, USA) to determine the percentage of phosphorous encapsulated in the ACM, which is correlated to the extractant $(500 \times, 3$ membranes prepared separately were analyzed).

\subsection{Batch studies}

Batch phenol removal experiments were carried out by immersion of $4 \mathrm{~cm}^{2}$ of ACM prepared as described in $30 \mathrm{ml}$ of a solution containing different concentrations of phenol. After the extraction, the remaining phenol in the aqueous solution was quantified in a capillary electrophoresis equipment (P/ACE system, MDQ Beckman Coulter, Brea, CA, USA) with UV detector (214 nm) as described by Bonoli et al. (22). Phenol extraction percentage $\left(\% \mathrm{E}_{\mathrm{Ph}}\right)$ was calculated according Eq. [1], where $\mathrm{C}_{\text {initial }}$ and $\mathrm{C}_{\text {final }}$ are the phenol concentration in the aqueous phase before and after the extraction process, respectively.

$$
\% \mathrm{E}_{\mathrm{Ph}}=1-\frac{\mathrm{C}_{\text {final }}}{\mathrm{C}_{\text {initial }}} \times 100
$$

Experiments carried out with the ICM do not show changes in the initial aqueous phenol concentration. For each value, the relative standard deviation in percentage (\%RSD) was calculated.

\subsection{Transport studies}

The cell used for the transport of phenol through the ACM consists of two compartments: one containing $200 \mathrm{ml}$ of phenol as the feed phase and the other with $200 \mathrm{ml}$ of $\mathrm{NaOH}$ at different concentrations as the stripping phase. In the center both compartments are connected through a hole $\left(11.34 \mathrm{~cm}^{2}\right)$ in which the ACM is placed.

All transport experiments were performed in duplicate at room temperature for $7 \mathrm{~h}$ under constant agitation. Samples from both compartments were analyzed every hour in order to measure the phenol concentration in both, feed and stripping phases. Phenol quantification was carried out in a UV/Vis Lambda 40 spectrophotometer (Perkin-Elemer, Waltham, MA, USA) at $510 \mathrm{~nm}$, as described by Woolard and Irvine (23). The percentage of phenol recovery $\left(\% R_{\mathrm{Ph}}\right)$ was calculated according Eq. [2], where $\mathrm{C}_{\text {feed,initial }}$ is the phenol concentration at the beginning of the experiment in feed phase, and $\mathrm{C}_{\text {stripping,end }}$ is the phenol concentration in the stripping solution after the transport process.

$$
\% \mathrm{R}_{\mathrm{Ph}}=\frac{\mathrm{C}_{\text {stripping,end }}}{\mathrm{C}_{\text {feed,initial }}} \times 100
$$


For each value, the relative standard deviation in percentage $(\%$ RSD) was calculated.

\section{Results and discussion}

\subsection{ACM characterization}

The ACM characterization was performed by Raman spectroscopy (Figure 1), obtaining information from each membrane layer. From the spectrum obtained for the polysulfone porous layer (Figure 1A); the vibrations corresponding to the $\mathrm{C}-\mathrm{H}$ bond can be observed at $3080 \mathrm{~cm}^{-1}$ as well as a double band at 1720 and $1613 \mathrm{~cm}^{-1}$ due to inplane benzene ring deformation. At $1272 \mathrm{~cm}^{-1}$ the asymmetric $\mathrm{C}-\mathrm{O}-\mathrm{C}$ stretching band is recognized, while the symmetric stretching mode occurs at $1149 \mathrm{~cm}^{-1}$. The band at $856 \mathrm{~cm}^{-1}$ is the result of asymmetric C-S-C stretching bond (24).

For ICM (ACM without extractant) (Figure 1B) the C-H stretching bands of piperazine appear at 3077, 2955 and $2757 \mathrm{~cm}^{-1}$. Frequencies 1629 and $1723 \mathrm{~cm}^{-1}$ are assigned to an in-plane benzene ring vibration corresponding to terephtaloyl chloride attached to piperazine molecules. The symmetric $\mathrm{C}-\mathrm{N}$ stretching vibration appears in the region $1090-1145 \mathrm{~cm}^{-1}$, while a weak intensity band at $628 \mathrm{~cm}^{-1}$ is assigned to C-C-N deformation vibration (25).
Finally, in ACM spectrum (Figure 1C) a band at $1415 \mathrm{~cm}^{-1}$ is observed due to $\mathrm{P}=0$ bond (in addition to the bands observed for the porous and dense layers) indicating the presence of Cyanex 923 encapsulated in the membrane.

\subsection{Batch studies}

The evaluation of the polyamide layer composition is important since this layer contains the immobilized extractant agent which makes the extraction process possible. In order to select the most suitable dense layer for phenol extraction, ACM characterization as well as the phenol batch extraction experiments and the accuracy of the readings obtained during $7 \mathrm{~h}$ of experimentation were taken into account. EDS analysis shows a higher percentage of phosphorus for piperazine-ACM (4\% of phosphorous atoms, $6.5 \%$ of RSD) which may be associated with a greater amount of encapsulated Cyanex 923. As a consequence, a higher amount of extracted phenol is reached $(43.08 \%)$. This may be due to the fact that an aromatic amine such as m-phenylediamine forms denser layers than alicyclic amines because of their more rigid structure (26). Thus, the denser is the layer, the less Cyanex 923 can be retained (3\% of phosphorous atoms, 8.9\% of RSD) and the phenol extraction decreases (35.39\%). Additionally, in the three experiments performed for each membrane

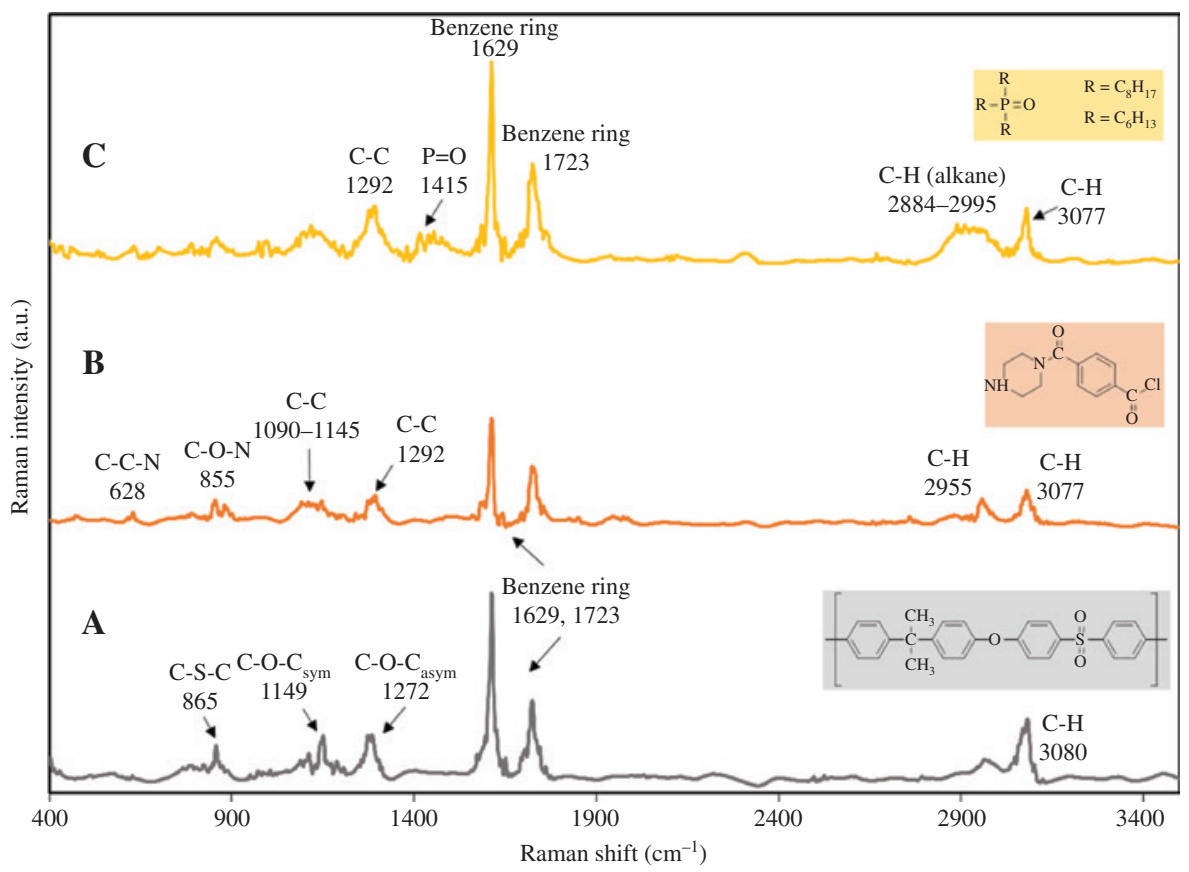

Figure 1: Verification of the presence of Cyanex in the activated composite membrane. Raman spectra for (A) Polysulfone porous layer, (B) ICM prepared with piperazine, and (C) ACM prepared with piperazine as dense layer and $2 \mathrm{~mol} \mathrm{l}^{-1}$ of Cyanex in casting solution. 
type, the sampling was performed over $7 \mathrm{~h}$ yielded readings with relative standard deviation (in percentage) ranging from 7 to $50 \%$ for 1,3-phenylenediamine while for piperazine they were no more than $7 \%$.

The carrier content in the membrane has a significant effect on the analyte extraction; in order to find the better preparation conditions concerning on Cyanex 923 content, several membranes were prepared from casting solutions at different extractant concentrations $\left(0.5-2 \mathrm{~mol} \mathrm{l}^{-1}\right)$. The effects of the Cyanex 923 content of the ACM on the phenol extraction are shown in Table 1. It becomes clear that phenol extraction becomes higher just when Cyanex 923 concentration reaches a $2 \mathrm{~mol} \mathrm{l}^{-1}$ value in the casting solution. It is important to note that was not possible to evaluate higher concentrations of Cyanex 923 due to the low solubility of acid chloride in organic media at the uppermost extractant amount. For this reason, $2 \mathrm{~mol} \mathrm{l}^{-1}$ concentration was used for the following experiments.

Once it was proved the feasibility of phenol extraction with ACM-Cyanex 923, the piperazine prepared membranes were used in transport experiments.

\subsection{Transport studies}

According to the literature the stripping phase is one of the key factors for effective transport; for this reason different concentrations of a strong base $(\mathrm{NaOH})$ were evaluated as stripping solutions in order to obtain the best re-extracting conditions for phenol transport. The use of this strong base would allow the membrane-extractedphenol to be released from the ACM due to the formation of sodium phenolate in the stripping phase (27).

Figure 2 shows that increasing the $\mathrm{NaOH}$ concentration increases the phenol transport. Nevertheless, with a $\mathrm{NaOH}$ concentration of $2.5 \mathrm{~mol} \mathrm{l}^{-1}$, the recovery of phenol decreases because of the swelling of dense membrane due

Table 1: Phenol extraction percentages obtained with ACM prepared at different Cyanex 923 concentration in the casting organic

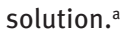

\begin{tabular}{lcc}
\hline $\begin{array}{l}\text { Cyanex 923 concentration in } \\
\text { casting organic solution }\left(\mathrm{mol} \mathrm{l}^{-1}\right)\end{array}$ & $\% \mathrm{E}_{\mathrm{Ph}}$ & $\%$ RSD \\
\hline 0.5 & 31.83 & 2.77 \\
1.0 & 40.24 & 1.28 \\
1.5 & 40.67 & 3.74 \\
2.0 & 44.17 & 5.90 \\
\hline
\end{tabular}

aExperimental conditions: membrane surface area, $4 \mathrm{~cm}^{2} ; 25 \mathrm{mg} \mathrm{l}^{-1}$ phenol in feed phase $(\mathrm{pH}=2)$; $\mathrm{ACM}$ prepared with piperazine. Values were obtained after $7 \mathrm{~h}$ counted from the start of the experiment.

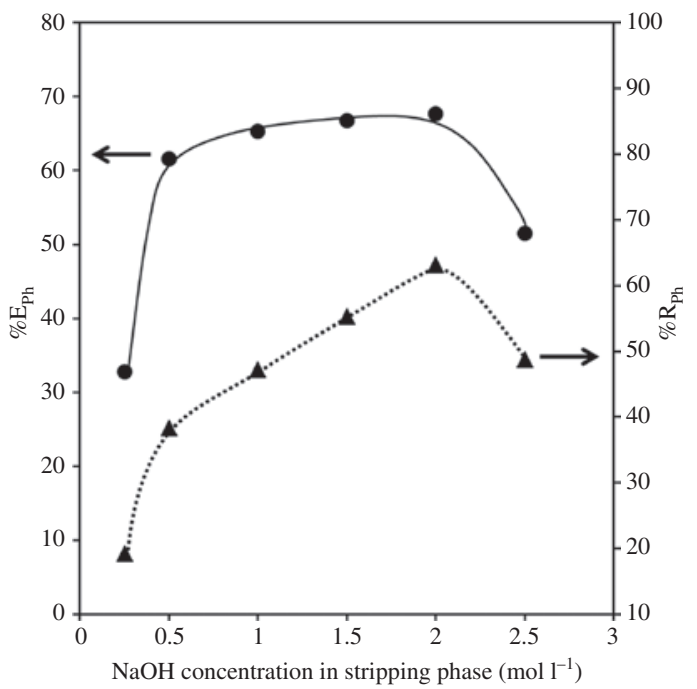

Figure 2: Effect of variation of the stripping phase $\mathrm{NaOH}$ concentration on phenol transport.

Experimental conditions: $25 \mathrm{mg} \mathrm{l}^{-1}$ of phenol in the feed phase $(\mathrm{pH}=2)$; ACM prepared with piperazine as a dense layer and $2 \mathrm{~mol}$ $\mathrm{I}^{-1}$ of Cyanex in the casting solution, $11.34 \mathrm{~cm}^{2}$ of membrane surface area. Values were obtained after $7 \mathrm{~h}$ counted from the start of the experiment. $0.28<\% R S D<11.90$.

to the extreme alkaline medium and the eventual extractant loss. This allowed choosing $2 \mathrm{~mol} \mathrm{l}^{-1}$ as the optimal concentration of $\mathrm{NaOH}$ for subsequent phenol recovery experiments.

In order to evaluate the influence of $\mathrm{pH}$ value of feed solution on phenol transport, several values of $\mathrm{pH}(2,3$, 5, 7, 9 and 11) were imposed by using $\mathrm{NaOH}$ or $\mathrm{HCl}$ solutions ( $25 \mathrm{mg} \mathrm{l}^{-1}$ phenol in the feed phase). As a result, a decrease of the extraction percentage at higher $\mathrm{pH}$ values was observed: an $87.41 \%(\% \mathrm{RSD}=3.34)$ of extraction percentage at $\mathrm{pH} 2$, and a $25.18 \%(\% \mathrm{RSD}=3.98)$ at $\mathrm{pH} 11$. This can be explained because phenolate (charged species) is the predominant species at $\mathrm{pH} 11$ and cannot be extracted by Cyanex 923, a non-polar compound. Also, as a consequence of the high extraction percentages in acidic conditions, more phenol is transferred to the ACM and as a result more phenol could be re-extracted to the stripping phase: $63.13 \%$ (\%RSD $=3.56$ ) of phenol transported to the stripping phase when $\mathrm{pH}$ in the feed phase was 2 , and $37.80 \%$ (\%RSD $=9.04)$ of the phenol transported to the stripping phase when $\mathrm{pH}$ in the feed solution was 11. For this, the $\mathrm{pH}$ value in the feed solution that favors the extraction is 2 and this value was imposed in subsequent experiments.

Additionally, experiments were performed to study the effect of the initial phenol concentration in the feed phase $\left(5,10,25\right.$ and $\left.50 \mathrm{mg} \mathrm{l}^{-1}\right)$ on its extraction and transport percentage. A $99.91 \%$ of the extraction percentage 
A

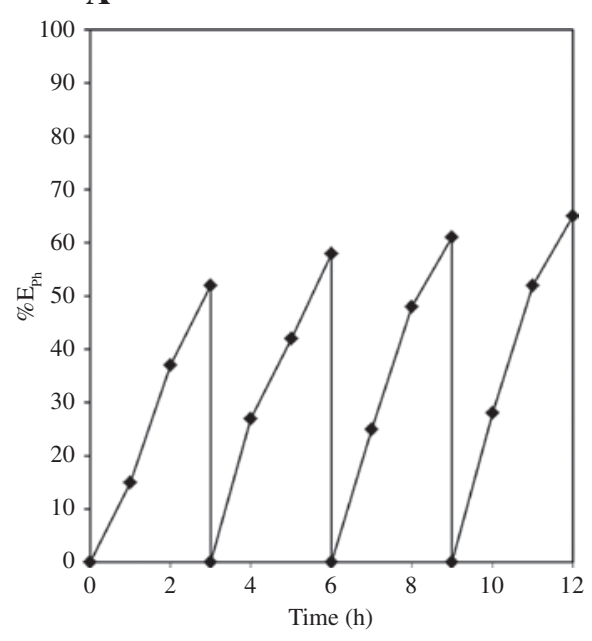

B

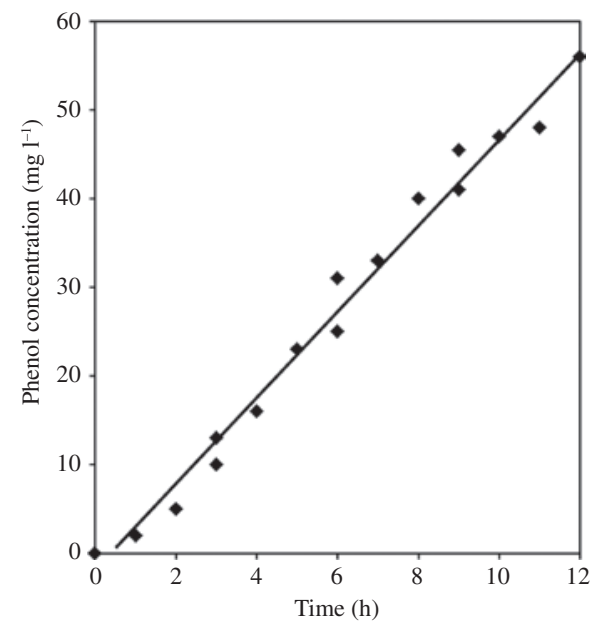

Figure 3: Continuous extraction though ACM.

(A) Phenol extracted from the feed phase to ACM; (B) phenol concentration observed in the stripping phase. Experimental conditions: initial $25 \mathrm{mg} \mathrm{l}^{-1}$ phenol in the feed phase $(\mathrm{pH}=2)$; ACM prepared with piperazine as the dense layer and 2 mol $\mathrm{l}^{-1}$ of $C y a n e x$ in the casting solution, $11.32 \mathrm{~cm}^{2}$ of the membrane surface area; $\mathrm{NaOH} 2 \mathrm{~mol} \mathrm{l}^{-1}$ in the stripping phase; $12 \mathrm{~h}$ of analysis time.

towards the membrane was obtained with an initial concentration of phenol of $10 \mathrm{mg} \mathrm{l}^{-1}(\% \mathrm{RSD}=14.04)$. However, it was observed that there is a decrease in the percentage of phenol extraction at the lowest $\left(5 \mathrm{mg} \mathrm{l}^{-1}\right.$; 85.99\% phenol extracted with 9.19 of \%RSD) and highest values (50 $\mathrm{mg} \mathrm{l}^{-1} ; 55.47 \%$ phenol extracted with 8.86 of \%RSD)

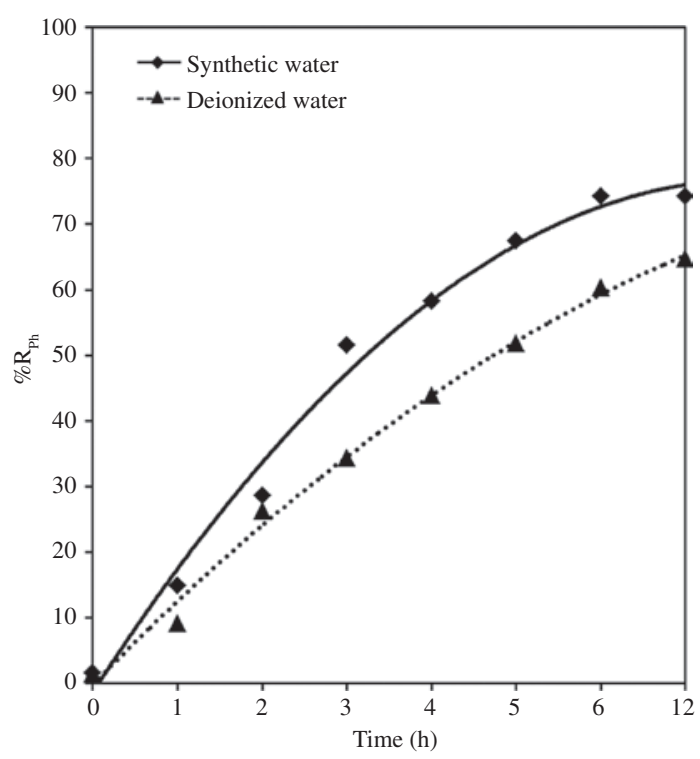

Figure 4: Comparative study of phenol transport between deionized water and synthetic wastewater.

Experimental conditions: $25 \mathrm{mg} \mathrm{l}^{-1}$ phenol in feed phase $(\mathrm{pH}=2)$; ACM prepared with piperazine as dense layer and $2 \mathrm{~mol} \mathrm{l}^{-1}$ of Cyanex in casting solution, $11.34 \mathrm{~cm}^{2}$ of membrane surface area; $\mathrm{NaOH}$ $2 \mathrm{~mol} \mathrm{l}^{-1}$ in stripping phase. tested. The latter case because the membrane capacity is exceeded, while at low concentrations there is a diffusional negative effect during the phenol extraction process. As far as transport is concerned, the differences were smaller, so it can be inferred that the determining step in the process is the extraction of the phenol to the membrane. Additionally it is interesting to appreciate that even at low phenol concentration, a facilitated transport is still carried out.

\subsection{Continuous extractions}

Concerning the study of phenol extraction during a continuous process, a volume of phenol solution was added to the feed phase every $3 \mathrm{~h}$ (three additions) so that the initial volume and concentration was restored to the initial values (200 ml and $25 \mathrm{mg} \mathrm{l}^{-1}$, respectively). The system was monitored observing that a percentage of the phenol extraction did not show significant changes during the four cycles (Figure 3A). Regarding the stripping phase (Figure 3B), there is a linear behavior indicating a transport mechanism that works with the same efficiency even after $12 \mathrm{~h}$ of continuous operation.

\subsection{Studies with synthetic wastewater}

The extraction and recovery of phenol with ACM from synthetic wastewater were conducted by doping water from an industrial park in Hidalgo state (México) with phenol 
Table 2: COD values for feed and stripping solutions in the phenol transport experiment. ${ }^{a}$

\begin{tabular}{lrrrr}
\hline System & \multicolumn{1}{c}{$\operatorname{COD}_{\text {initial }}\left(\left.\mathbf{m g}_{\text {oxygen }}\right|^{-1}\right)$} & & $\operatorname{COD}_{\text {final }}\left(\mathrm{mg}_{\text {oxygen }} \boldsymbol{l}^{-1}\right)$ \\
\cline { 2 - 5 } & Feed phase & Stripping phase & Feed phase & Stripping phase \\
\hline Deionized water & 68.29 & 3.85 & 20.76 & 40.97 \\
Synthetic wastewater & 673.71 & 1.14 & 564.51 & 68.63 \\
\hline
\end{tabular}

aExperimental conditions: initial $25 \mathrm{mg} \mathrm{l}^{-1}$ phenol in the feed phase $(\mathrm{pH}=2)$; ACM prepared with piperazine as the dense layer and $2 \mathrm{~mol}^{-1}$ of Cyanex in the casting solution, $11.32 \mathrm{~cm}^{2}$ of the membrane surface area; $\mathrm{NaOH} 2 \mathrm{~mol} \mathrm{l}^{-1}$ in the stripping phase. $7 \mathrm{~h}$ of analysis time.

(25 mg l-1), urea $\left(0.5 \mathrm{mg} \mathrm{l}^{-1}\right), \mathrm{KH}_{2} \mathrm{PO}_{4}\left(0.3 \mathrm{mg} \mathrm{l}^{-1}\right)$ and formaldehyde $\left(23 \mathrm{mg} \mathrm{l}^{-1}\right)$, with the aim of simulating wastewater from resin production plants (28). Figure 4 shows that the percentage of phenol recovery in the stripping phase is higher when using synthetic water due to the components in the feed phase increasing the ionic strength, improving the phenol transport.

To evaluate the selectivity of ACM in the phenol extraction and transport, a chemical oxygen demand (COD) analysis was performed for both phases (feed and stripping phase) (Table 2). Results show a change attributable mainly to the amount of phenol transported as only $3 \%$ of the other components present in the simulated wastewater was transported to the discharge phase. Therefore it can be concluded that the process shows a high preference for the analyte of interest.

\section{Conclusions}

In this study, the facilitated transport of phenol through a novel ACM containing Cyanex 923 was investigated. According to the results, it was possible to develop a new configuration of the ACM with a dense piperazine layer that facilitates the transport of phenol and is less rigid than the conventional ACM prepared from 1,3-phenylendiamine.

In the transport experiments, sodium hydroxide concentration in the stripping phase plays an important role as at higher $\mathrm{NaOH}$ concentration, phenol transport is facilitated. However, an excess of this causes a loss of the extractant agent thus affecting the transport process. The $\mathrm{pH}$ value in the feed phase also has a great influence in the ACM extraction due to the acid-base phenol properties and the mechanism of extraction that requires phenol in its neutral form, that is, protonated.

It is important to mention that the extraction and transport of phenol is favorably affected when the feed phase has a high ionic strength. This is an advantage when using real solutions, generally complex in their composition and with a high ion concentration. Concurrently, the same ACM can be reused up to three cycles without presenting important changes in the amount of phenol transported, which makes this a feasible method for the recovery of phenol.

Acknowledgments: MEPH acknowledges CONACyT (Funder Id: 10.13039/501100003141, 2006-62581 project) and PROMEP (SEP, Mexico) for the financial support. IPS, MEPH, CAGV, GAAR and MTRS gratefully thank the SNI for the distinction of their membership.

\section{References}

1. Cordova Villegas LG, Mashhadi N, Chen, M, Mukherjee D, Taylor KE, Biswas N. A short review of techniques for phenol removal from wastewater. Curr Pol Rep. 2016;2(3):157-67.

2. Agency for Toxic Substances and Disease Registry ATDSR, Toxic Substances Portal - Phenol; Atlanta, USA [Internet]. Revised 2017, Nov 5; Available from https://www.atsdr.cdc.gov/phs/phs. asp?id=146\&tid=27\#bookmark092008.

3. Official Mexican Standard NOM-127-SSA1-1994. Environmental health, water for human use and consumption - permissible quality limits and treatments to which water must be subjected for its purification, Ministry of Health; México City, México [Internet]. Revised 2017, Nov 5; Available from http://www.salud.gob. $\mathrm{mx} /$ unidades/cdi/nom/127ssa14.html.

4. Mohammadi S, Kargari A, Sanaeepur H, Abbassian K, Najafi A. Phenol removal from industrial wastewaters: a short review. Desalin Water Treat. 2015;53(8):2215-34.

5. Esplugas S, Giménez J, Contreras S, Pascual E, Rodríguez M. Comparison of different advanced oxidation processes for phenol degradation. Wat Res. 2002;36(4):1034-42.

6. De Luis AM, Lombraña JI, Menéndez A, Sanz J. Analysis of the toxicity of phenol solutions treated with $\mathrm{H}_{2} \mathrm{O}_{2} / \mathrm{UV}$ and $\mathrm{H}_{2} \mathrm{O}_{2} / \mathrm{Fe}$ oxidative systems. Ind Eng Chem Res. 2011;50(4): 1928-37.

7. Rodriguez I, Llompart MP, Cela R. Solid-phase extraction of phenols. J Chromatogr A. 2000;885(1-2):291-304.

8. Burghoff B, Goetheer ELV, Haan AB. Solvent impregnated resins for the removal of low concentration phenol from water. React Funct Polym. 2008;68(9):1314-27.

9. Kabay N, Cortina JL, Trochimczuk A, Streat M. Solventimpregnated resins (SIRs) - Methods of preparation and their applications. React Funct Polym. 2010;70(8):484-96. 
10. Soto ML, Moure A, Domínguez H, Parajó JC. Recovery, concentration and purification of phenolic compounds by adsorption: a review. J Food Eng. 2011;105(1):1-27.

11. Oleinikova M, González C, Valiente M, Muñoz M. Selective transport of zinc through activated composite membranes containing di(2-ethylhexyl)dithiophosphoric acid as a carrier. Polyhedron 1999;18(25):3353-9.

12. Gumi T, Oleinikova M, Palet C, Valiente M, Muñoz M. Facilitated transport of lead(II) and cadmium(II) through novel activated composite membranes containing di-(2-ethyl-hexyl)phosphoric acid as carrier. Anal Chim Acta. 2000;408(1-2):65-74.

13. Resina M, Fontás C, Palet C, Muñoz M. Selective transport of platinum(IV) and palladium(II) through hybrid and activated composite membranes containing Aliquat 336. Desalination 2006;200(1-3):100-2.

14. Melita L, Popescu M. Removal of $\mathrm{Cr}(\mathrm{VI})$ from industrial water effluents and surface waters using activated composite membrane. J Membr Sci. 2008;312(1-2):157-62.

15. Arslan G, Tor A, Cengeloglu Y, Eroz M. Facilitated transport of $\mathrm{Cr}(\mathrm{III})$ through activated composite membrane containing di(2-ethylhexyl)phosphoric acid (DEHPA) as carrier agent. J Hazard Mater. 2009;165(1-3):729-35.

16. Mendoza-Tolentino Y, Galán-Vidal CA, Álvarez-Romero GA, Ramírez-Silva MT, Páez-Hernández ME. Earliest results in the use of activated composite membranes for the transport of silver ions from aqueous solutions. J Chem. 2014;2014. Article ID 467526.

17. Reis MTA, Freitas OMF, Agarwal S, Ferreira LM, Rosinda M, Ismael C, Machado R, Carvalho JMR. Removal of phenols from aqueous solutions by emulsion liquid membranes. J Hazard Mater. 2011;192(3):986-94.

18. Gutiérrez R, Urtiaga A, Ortiz I. Separation of phenol and formaldehyde from industrial wastes. Modelling of the phenol extraction equilibrium. J Chem Technol Biotechnol. 2010;85(9):1215-22.
19. Cichy W, Scholosser S, Szymanowsky J. Recovery of phenol with CYANEX® 923 in membrane extraction-stripping systems. Solvent Extr Ion Exch. 2001;19(5):905-23.

20. Garea A, Urtiaga AM, Ortiz MI, Alonso AI, Irabien JA. Phenol recovery with SLM using Cyanex 923. Chem Eng Comm. 1993;120(1):85-97.

21. Benavente J, Oleinikova M, Muñoz M, Valiente M. Characterization of novel activated composite membranes by impedance spectroscopy. J Electroanal Chem. 1998;451(1-2):173-80.

22. Bonoli M, Montanucci M, Toschi T, Lerecker GG. Fast separation and determination of tyrosol, hydroxytyrosol and other phenolic compounds in extra-virgin olive oil by capillary zone electrophoresis with ultraviolet-diode array detection. J Chromatogr A. 2003;1011(1-2):163-72.

23. Woolard CR, Irvine RL. Treatment of hypersaline wastewater in the sequencing batch reactor. Water Res. 1995;29(4): 1159-68.

24. Gordeyev SA, Nikolaeva GY, Prokhorov KA, Withnall R, Dunkin IR, Shilton SJ, Pashinin PP. Super-selective polysulfone hollow fibre membranes for gas separation: assessment of molecular orientation by Raman spectroscopy. Laser Phys. 2001;11(1): $82-5$.

25. Gunasekaran S, Anita B. Spectral investigation and normal coordinate analysis of piperazine. Indian J Pure Appl Phy. 2008;46(12):33-8.

26. Song Y, Liu F, Sun B. Preparation, characterization, and application of thin film composite nanofiltration membranes. J Appl Polym Sci. 2005;95(5):1097-4628.

27. Ng YS, Jayakumar NS, Hashim MA. Performance evaluation of organic emulsion liquid membrane on phenol removal. J Hazard Mater. 2010;184(1-3):255-60.

28. Tišler TJ, Zagorc-Končan J. Comparative assessment of toxicity of phenol, formaldehyde, and industrial wastewater to aquatic organisms. Water Air Soil Poll. 1997;97(3-4):315-22. 